\title{
The professional learning of further education lecturers: Effects of initial lecturer education programmes on continuing professional learning in Scotland and Wales.
}

\author{
Dr Gary Husband \\ University of Stirling \\ Faculty of Social Sciences \\ gary.husband@stir.ac.uk
}

\begin{abstract}
This paper reports on the results of a research study conducted in two colleges of further education in Scotland and Wales. The aim of the study was to begin to understand the ongoing effects of initial lecturer education programmes. Using the accounts of respondent lecturers and detailed documentary analysis, an accurate picture of the professional learning provision in the two colleges and devolved sectors was constructed. The research found that induction practices, mentor support, model of initial lecturer education programmes and engagement with practice focused work based learning all had significant impacts on ongoing engagement with professional learning. The paper concludes with suggestions for practice related to the structuring of professional learning from induction to continuous career long provision.
\end{abstract}

\section{Key words:}

Further education, vocational teachers, work based learning, lecturer education, professional learning, lecturer initial education.

Accepted for publication in Research in Post-Compulsory Education published by Taylor and Francis. 


\section{Introduction}

This paper focuses on the longer term effects of initial teacher education on the professional learning of further education (FE) lecturers in Scotland and Wales. As O'Brien, (2016) highlights, there are many published studies that focus on the immediate experiences of individuals undertaking training ${ }^{1}$ programmes and lecturer education courses, but little review of the longer term impacts of how differing interventions or existing practice are enacted within organisational structures. This study seeks to begin to address the paucity of published research in this area and open discussion surrounding the connections between models of initial professional education and the impact upon engagement with ongoing professional learning. This study builds on a previous small scale case study carried out by the researcher for a college in Scotland. The researcher has over ten years' experience of teaching and leadership in FE in both Scotland and Wales and prior to leaving FE was the professional development manager in a large multi campus college in Scotland. In carrying out the duties related to previously held roles, the researcher became interested in the efficacy and effect of initial teacher education programmes. The role related work in FE led to this study being conducted as a larger scale project encompassing the two devolved sectors in Scotland and Wales, of which the researcher has previous experience and both practice and policy based expertise.

Several significant issues are explored in the literature that highlight the potential implications of initial training and education programmes on professional practice. Bathmaker \& Avis (2005) in a study of 100 trainee lecturers undertaking teaching placements as part of study towards Professional Graduate Certificate of Education (PGCE, undergraduate level FE specific teaching qualification), highlight difficulties related to integration within communities of practice (Wenger \& Lave 2002). Although trainee lecturers were engaging in relevant learning related to the role of a lecturer, the researchers highlight that the longer term implications of barriers to integration and acceptance into an established community are of significance. When the ongoing formation of professional identity and new forms of professionalism of both trainees and experienced lecturers is considered, their findings suggest a significant impact of the training courses of ongoing engagement with developing practice. This theme is further explored by Orr \& Simmons (2010) when they conducted a smaller scale study involving a little over twenty managers and trainees in two colleges of further education. They identified issues related the expectation of an ability to manage dual identities as both trainee and lecturer. They further identified that much of the supplied training offered solutions to developing coping mechanisms to manage learning in a challenging and unsupportive environments. The study

\footnotetext{
1 The use of the word 'training' when describing teacher education programmes is contested (a useful summary of literature related to this is provided by Asif, 2013). However, 'training' forms part of the language used within FE to describe initial and continuing education programmes for lecturers and as such, where necessary is used within this paper.
} 
concluded that the ideals presented within the training programmes themselves did not match the realities of the practice experienced within placements.

Orr (2012) goes on to further explore these themes when conducting a subsequent study looking at both pre-service and in service trainees studying for teaching qualifications in FE in England. Orr draws attention to the potential for limited learning as a trainee lecturer where the focus is on standards based curriculum as opposed to a knowledge based approach. Lecturers reported that they felt that they had learned to cope instead of learning to teach. Again, this draws significant attention to the longer term implications for the consideration of impact of training on practice beyond the immediate requirements to fulfil allocated and full teaching loads. This is again highlighted by Maxwell (2014), who conducted a comparative analysis of eleven previous studies that all focused on the work based learning experiences of trainee lecturers. In summarising the findings of all eleven studies Maxwell highlights the paucity of support for appropriately constructed and integrated learning opportunities for trainees in their places of work. Although acknowledging the tentative nature of the findings, Maxwell (ibid) draws attention to the fact that affordances of lecturers work based teaching experience is essential for trainee development.

In reviewing the research literature related to the field of lecturer education and initial training courses for FE practitioners, it is evident that researchers have repeatedly identified the importance of work based learning and continuing career development opportunities. It is evident in the reviewed literature that to consider the university based provision for teacher education programmes for lecturers as a panacea for all professional formation and initial training requirements, would be misguided. Indeed, Maxwell (2014) highlights the need for the broader aspects of professional formation to be essential in the initial and continuing development of FE professionals.

\section{This research study}

This work was conducted within the FE sector in Scotland and Wales in the UK and sought to address the following question:

- Does the enactment of initial lecturer teacher education programmes in FE have an effect on respondents engagement with, and choices of, ongoing professional development?

This research provides an insight into some of the influences on professional learning choices of lecturers working in FE by exploring:

- The construction (in policy and curriculum) and enactment of initial teacher education programmes

- The accessibility and provision of planned training activities 
- The role and influence of mentors and peers on trainee colleagues

- The effective links between work based learning and practice and influence on further learning requirements

This study seeks to begin to understand the links between the enactment and content of initial education provided to lecturers and the impact it may subsequently have had on their practice and continued engagement with, and choices of, professional learning and development.

This study provides an important insight into the experiences of, and influences on, individuals accessing professional learning on completion of initial teacher education in FE in Scotland and Wales. Whereas the traditional focus in much research on FE is England, this research is original because it explores the relatively under-represented contexts of the rapidly changing further education and devolved sectors in Scotland and Wales. The research offers further important insights into the experiences of lecturers as they navigate professional learning within the unsettled and change driven environment of merger and shifting policy context of further education in Scotland and Wales. These insights, although derived from specific examples, also offer opportunities to consider the parallels in established practice in the broader international context of further and vocational education sectors.

\section{Initial lecturer education as professional learning.}

As highlighted by Lucas \& Unwin (2009) there is a tendency within FE in the UK to discuss initial education programmes for lecturers and continued professional learning as discrete entities i.e. career long professional learning starts after the initial discrete training phase has ended. This is evidenced in the delineation of both the literature surrounding initial education programmes and career long professional education, and the form that these processes and procedures take within many FE providing organisations. This provides an interesting cultural backdrop to this research as the models of both initial training and continued professional learning studied, closely mirrored each other within each studied organisation but were treated as separate entities with much continued professional learning delivered in discrete packages, often by external providers. It is therefore of little surprise that a shift towards a reliance on partner organisations, often higher education institutions (HEIs) to deliver fully qualified and productive staff, could potentially serve in many instances to remove the impetuous for applied and work based learning to form a central part of induction and probation programmes.

Increasingly, courses provided by HEIs are focusing on the vocational and work based aspects of lecturer education and development using applied experience as evidence for assessment purposes (see University of Dundee, 2015; University of Stirling, 2015 for examples). However, as Maxwell (2014) discusses, workplace learning is an important and significant factor in the provision of lecturer 
education programmes. The practical and cultural support for this within FE organisations is critical and intractably linked to the efficacy of professional formation and organisational and professional development. As a potentially useful analogy, it is seemingly not possible to become a competent car mechanic or chef purely by reading a manual or completing on line tutorials, so it follows that the practical and vocationally acquired skills set of further education lecturers cannot be developed through theoretical immersion alone. Although an important aspect of training and professional formation, even university based courses focusing on practical and vocational practice, are potentially unable to fully supply all aspects of training and development simply because of time and resource constraints. As with an apprentice model (Fuller \& Unwin 2014), novice lecturers need both appropriate theoretical instruction and a variety of applied and supported work based learning opportunities in order to develop the required tacit skills and confidence in practice, a duality in approach to learning both 'on and off the job' (Lucas \& Unwin 2009).

Oude Groote Beverborg, Sleegers \& van Veen (2015) in a useful summary of research conducted into professional learning in schools and colleges concluded that the not only were factors such as selfefficacy and autonomy important to effective professional learning, but also recognition that leadership and structured learning have significant impact on the efficacy and impact of initial education programmes and continued learning opportunities for lecturers. This in itself may seem to be self-evident and taken for granted, but the impact on organisations, individuals and consequently the student body is poorly theorized and not fully understood.

The models designed by organisations (and leaders within them), that contain and make up the overall structured approach to professional learning and initial education are therefore then potentially as important as the discrete courses themselves (see Oude Groote Beverborg, Sleegers \& van Veen, 2015 for example).

The interactions between interdependent provision, concurrently undertaken, can be seen to have an influence on the individual that should be taken into consideration by those designing and delivering both work based and theoretically grounded learning. As Filliettaz, Durand \& Trebert (2015) explore, there are a series of complex relations between learning and work and professional learning that cannot be said to exist solely within the paradigm of designed and provided training courses. A rich and diverse spectrum of professional learning comes through immersion in practice and community, a mixture of both formal and informal learning (Eraut 2004) through prescribed courses and from experienced colleagues (Eraut 2007).

As problematic as it is for many practitioners in further education that leave industry one day and are teaching the next, the full immersion in practice is seen by many colleges as an important part of the training process. However, this happens infrequently as a result of designed practice and is more often related to a requirement and necessity for individuals to be productive from the onset of a contract, 
novice status is simply no longer widely recognised in many parts of the FE sector in the UK (Husband 2015), or at least not conditionally. The immersion and embedding of individuals within busy working environments invites opportunities for informal learning to occur through contact with (often) more experienced peers (Eraut 2007). Slade (2011) argues that the practice of work based learning and development, although more structurally intended and supported, forms the basis of much training in public service professions such as the police. The work based and practice focussed elements of training programmes allow for the tacit and experienced based learning of peers to play a greater role in the development opportunities of less experienced and qualified colleagues. Mentoring, both formally and informally, as part of induction and professional learning in FE, can play an important part in the professional development opportunities of those new to practice (Page 2013) and indeed, those who have moved beyond the perceived initial stages of learning in often discrete models of initial training and continued development.

Unlike much of the compulsory education sector that often employs subject specific teacher education, further education largely utilises generic programmes where specialists from many differing subject areas will learn and train together (Avis et al. 2012). The use of mentoring often allows for a subject specific specialist to provide the support required for specific pedagogies to be developed and curriculum based knowledge such as assessment practice to be shared, although as Ingleby (2011) points out, mentors are often used in judgemental and not developmental capacity which may limit this phenomenon. Further to the practicalities of teaching practice, the engagement with peers and mentors within departmental and subject specific areas may also promote the development of local cultural capital and the ability to assimilate and ultimately impact the broader collective organisation (Brandon \& Charlton 2011).

The structure and design of initial lecturer education courses in FE as collective programmes with discrete but interdependent constituent parts, offers the ability to expose those undertaking the structured learning to theoretical instruction, work based practiced and experience, through collaboration with mentors. As Maxwell (2014) argues, one provider of one element of training cannot be held accountable for the perceived success or failure of the whole programme.

How these grouped learning opportunities are managed and implemented in partnership with external providers, internal stakeholders, curriculum leaders and the student lecturers themselves, may play a critical part in the success or failure of the overall initial learning experience and transition into, and impacts on, engagement with continued professional learning. 


\section{Study Design and Research Framework}

This study was designed to see if the enactments and content of initial lecturer teacher education programmes in FE can have any effect on respondents engagement with ongoing professional learning. In order to carry out this investigation, two case studies in two separate colleges of further education were conducted.

\section{The colleges}

The study was a non-funded project and as such had limited resource with which to engage large numbers of respondents. In order to secure sufficient data for analysis it was decided to conduct a two case study site project. Two large, similarly structured colleges, working in different devolved sectors of the UK provided suitable opportunities to engage with respondents and study the different methods employed to provide initial lecturer training and continued professional learning opportunities.

Selecting colleges of a similar size, sector position (quality inspection outputs, student numbers, staff roll call) and curriculum were important features for comparison between potentially suitable organisations. Agreement was secured for organisation 1 in Wales and this was then used to match organisation 2 in Scotland.

Both organisation 1 and 2 operate over multiple campuses and serve in excess of 15,000 students each. Over 1000 staff are employed in all areas of operation in both colleges and curriculum offerings are typical of large FE colleges. Comprising of a large range of specialisms, both colleges cover the arts, technology, social sciences, access courses and health and care studies from school through to university academic levels.

Organisation 1 covers a very large geographical area of Wales including both urban and rural settings with students from diverse demographics from some of the most deprived and affluent post codes. Organisation 2 is similar in size, is slightly less spread out geographically but covers a major urban centre, again, demographics are very diverse spanning some of the most affluent and deprived post code areas in Scotland.

\section{The respondents}

A purposive sample from the two colleges was selected via access through named contacts in senior executive management positions who circulated the call for research volunteers. Utilising a purposive sampling technique (Tongco 2007) for respondent selection allowed for specific criteria to be met (e.g. length of time post-graduation from teaching qualification) and avoided contacting unsuitable candidates. All those who responded were invited to take part. 24 initial responses were received between the two colleges with 2 people from each choosing not to continue due to workload and timing issues. The final twenty respondents included only individuals that had completed their required training and were classed as fully qualified by their employing organisation. The respondents 
had completed a minimum of 3 years teaching post initial education programme graduation and were all in current and active roles that included timetabled teaching. Of the 20 respondents, 10 were male and 10 were female ( 5 males and 5 females in each college). The respondents were all between 28 and 58 years of age. Three of the respondents, although still actively engaged in teaching at the time of interview, also held promoted posts with line management responsibilities for lecturing staff and curriculum. A range of subject specialisms were represented and although not specifically sought out, a representative sample of a diverse group of subjects (across the arts, social sciences, technology and humanities) was desirable and achieved.

\section{Interviews}

Using a methodological framework influenced by the principles of phenomenological hermeneutics (van Manen 1990; Gadamer 1998), semi structured interviews were used to capture the professional experiences and opinions of the respondents. Emotional and non-verbal responses coupled with environmental data was captured in accompanying field notes and used in the analysis of responses given. Using semi structured interviews allowed for individual agency to be captured alongside the emotive responses to many of the issues highlighted areas of stress or frustration in practice (Drever 2003; Yin 2011). As the interviews were designed to enable critical reflection and could stimulate emotive responses, it was ensured that informed consent was gained and that the BERA (2011) ethical guidelines formed the central premise around which respondent interaction, data analysis and reporting was designed and conducted. The University of Bangor (the organisation under whose banner the research was conducted) ethics committee fully supported and endorsed all aspects of the project. Information sheets were supplied (bilingually in Wales) to all respondents which gave clear an unambiguous descriptions of research aims and the methods to be used. Contact information for the researcher was supplied to allow for questions to be raised prior to the interviews.

The interviews were conducted over several months in 2014/15 and covered aspects of training, practice, ongoing professional learning, access to training, support for learning and influences on development and career choices. As the interviews progressed and thematic patterns emerged the interviews were modified to include further questions that picked up on these threads of interest and provided further data in relation to the new lines of questioning. 


\section{Document analysis}

In order to establish an accurate understanding of the training offered and provided by each organisation, a document analysis was undertaken. Documents including college policy, programme plans, quality assurance reviews and induction plans were all provided by the participating organisations (see Table 1).

\section{Table 1}

\begin{tabular}{|l|l|}
\hline College 1 in Wales & College 2 in Scotland \\
\hline Staff induction handbook (2015) & New staff induction handbook (2010/11 legacy college) \\
\hline Staff training policy 2013 & Academic staff initial training and CPD policy 2012 \\
\hline PGCE programme specification (licensing university) & $\begin{array}{l}\text { PDA (Level 8) specification and curriculum (SQA) } \\
\text { TQFE (University provider programme specification) }\end{array}$ \\
\hline Human resources training plans & Human resources training check list \\
\hline Quality assurance documents (2013) & Quality assurance review documents (2012-2014) \\
\hline All staff CPD programme of events (2014) & In service staff training day programme (2014) \\
\hline Strategic aims policy documentation & Regional outcome agreement \\
\hline Mentor handbook & \\
\hline
\end{tabular}

The documents were then used to accurately detail the expected training, induction and ongoing professional learning plans that staff in each organisation would theoretically be expected to follow. Systematic analysis was used to identify specific details that constructed the organisations expectations of its employees in relation to the specific outcome of becoming a fully inducted and qualified member of the teaching team. This was undertaken to ensure that the researcher was familiar with and aware of the specific expectations placed on each of the respondents in relation to their professional learning. The data was also used to ascertain (by cross referencing interview and documentary data) how the expected programme of professional learning had been implemented, reviewed and undertaken. Using the provided documents was a valuable addition to the research as it provided specific context, gave information that was fixed and free from researcher influence (Bowen 2009) and although unique in content to each organisation, it revealed that training provision largely followed a specific and common format. 


\section{Analysis}

As described by Crist \& Tanner (2003) thematic analysis of interview data using a framework of phenomenological hermeneutics took several steps. The initial interviews conducted were treated as pilots with feedback from respondents used to modify the interview schedule. Post pilot interviews had additional questions which, where possible, were put to initial respondents for comment and response. This process demonstrates the organic process of a phenomenological hermeneutic approach to the research and allowed for areas of importance and concern to emerge from the data, thus analysis began and occurred both concurrently and consecutively. The research questions themselves evolved during this process and as such at the start of the research, an area of interest was defined and the questions themselves became more fixed at the culmination of the analytical process. Thematic analysis normally involves a constant comparative method, meaning a continuing and progressive process of classifying, comparing, grouping and refining groupings of text, audio or video segments to create and then clarify the definition of categories, or themes, within the data. In this sense, this thematic analysis focused on building categories, derived inductively from the data, rather than from a hypothesise, which enabled systematic description (Fossey et al. 2002). Once all of the interviews had concluded it was possible to then finish the thematic analysis of the collated data using Nvivo software to manipulate and code the audio recordings of the interviews. It was possible to carry out a thorough digitally coded thematically analytical process which involved repeated review of the 15 hours of recorded data. Grouping and regrouping responses aided in the identification of keywords, phrases and responses which then formed the final thematic outputs of interest reported on here.

The document analysis comprised of several sessions reviewing the outlined programmes and structures of professional learning and cross referencing between document types (e.g. published college policy and training programme). It was possible to construct a model of the variables within the training programmes between the two organisations thus outlining the expected criteria required to be seen as 'fully qualified' within each organisation. On supplying the documents, organisational administration and management were able to provide some further clarity in relation to some minor items omitted from or not clear in the documents themselves.

\section{Findings}

The following section details the findings of both the document analysis and the interviews with respondents. All given names are pseudonyms. To maintain anonymity extracts from documents are not included. Summaries are provided and findings presented graphically.

\section{Themes emerging from analysis of documentary and interview data.}

In relation to the research question, does the enactment of initial lecturer teacher education programmes in FE have an effect on respondents engagement with, and choices of, ongoing professional development? Four main themes emerged from the combined data. 
- The constructed programmes of intended initial teacher education in each organisation did not seem to match the enacted practices.

- Accessibility to training programmes and enacted model seemed to have an impact on professional learning choices of lecturers engaged with training and ongoing professional learning.

- Both formal and informal (non college assigned) mentors were seemingly influential in the training programmes and could influence subsequent choices made by graduate lecturers.

- The links made by student lecturers between academic learning and practice based learning were not consistent between organisations and potentially influenced engagement with professional learning.

The following findings are presented within these themes leading to discussion regarding the enactment of training practices within the studied colleges and exploration of the possible broader implications for professional learning of lecturers in FE.

\section{Policy and curriculum constructed models of initial lecturer education}

The analysed documents showed that the scope of training for new teaching staff in each college was constructed from several sources and no one single document allowed for a complete process to be established or understood. It was possible to ascertain the processes and structures reportedly utilised in both colleges through engagement with published college policy, programme teaching plans and information supplied by relevant managers and learning support staff. College 1 had a more coherent structure for new staff to follow presented in the staff training policy, however (as with College 2) significant detail of the proposed study routes and requirements had to be drawn from accompanying documents. The purpose and aims of training programmes were stated in broader policy documents such as the regional outcome agreement of college 2. Figure 1 (below) shows the constructed constituent parts of the published programmes of both colleges and details the significant similarities between the reported programmes.

Figure 1:

Documented and published professional formation models employed in each studied organisation
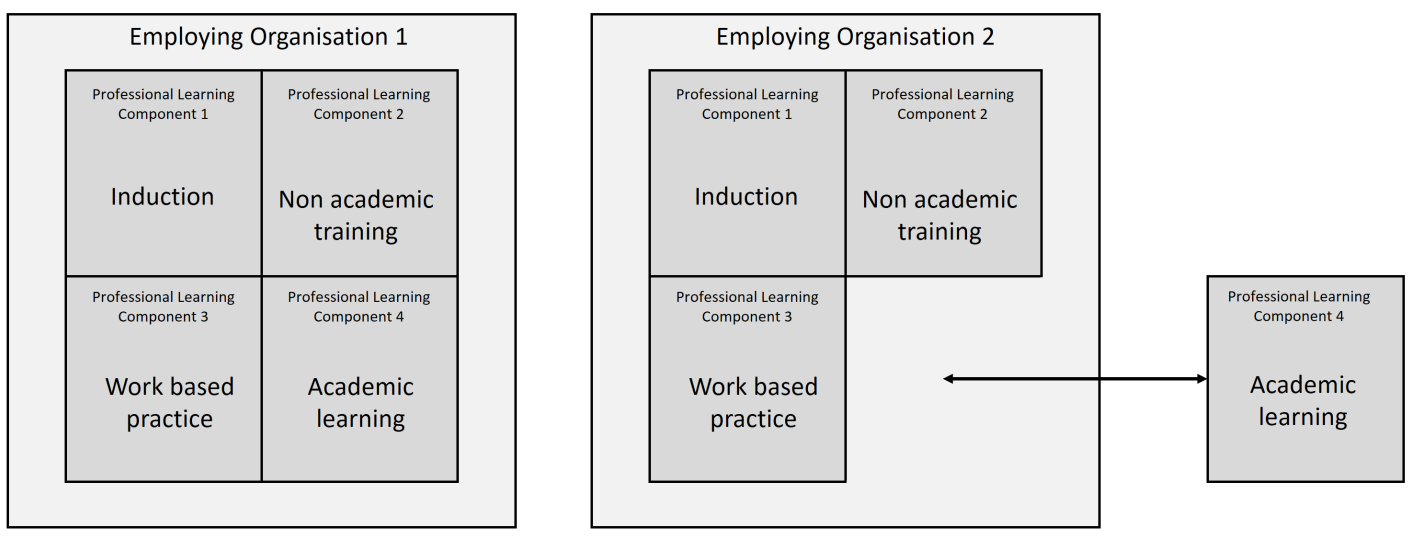
These models will be returned to in greater detail and given further scrutiny later in this paper but brief explanation of the various elements at this stage will illuminate the intervening discussion and subsequent research findings.

Both colleges reported relying on an in depth and comprehensive programme of induction activities for all staff, these reportedly formed a significant proportion of the introductory and developmental experience of all new staff. Both colleges published plans and policy detailing that induction would be cross curricular, interdisciplinary and common to all levels within the organisations. Inductions were billed as an opportunity to acclimatize to the new environment, learn the basics required to begin to engage with more complex requirements and crucially, to be welcomed. Induction was to be organised centrally and candidates automatically invited as part of the employment process.

Opportunities to assess prior learning and agree on appropriate and required training and developmental courses were reportedly discussed and professional learning plans drawn up alongside the completion of a list of induction priorities and tasks. Following the extended induction process both colleges reported that where required, places on lecturer education programmes (academic learning) would be secured, mentors would be assigned to support work based practice and any required non-academic training (assessors awards, verifiers awards ${ }^{2}$ and health and safety training as examples) would be agreed and scheduled appropriately. As can be seen from the diagram the only major difference between the reported models was the use of an external provider to deliver the academic elements of the programme for organisation 2 . This diagram presents a slightly simplistic view of this partnership work as organisation 1 engages with an external partner HEI to deliver the academic learning, but uses its own staff to deliver the programme under licence. Organisation 2 does not undertake any of the delivery of the university based programme which is delivered entirely outside of the college.

The document analysis served to provide sufficient data with which to reconstruct the idealised and planned structures for programmes of professional learning from initial induction through to ongoing professional development. This however, as will be reported in the following section, differed significantly from what was achieved and available to staff in practice.

\section{Accessibility of training provision and enactment of stated policy}

Both of the colleges had within the last three years undertaken large restructures and mergers. Organisation 1, located in Wales had been involved in several sustained years of merger and restructure with over ten campuses in locations across a large geographical area under the banner of

\footnotetext{
${ }^{2}$ Assessors and Verifiers awards are portfolio based short training courses originally aimed at training industry employed staff in assessment practices to support work based assessment.
} 
the newly formed organisation. Organisation 2, located in Scotland, was a new organisation arising from the merger of three large colleges.

Figure 1 (above) shows the published constituent parts of initial training programmes offered by both colleges but does not show them in relation to each other in terms of focus, reliance and use. When the models employed were reviewed in practice, and upon analysis of respondent's descriptions, a somewhat different picture of practice emerged in both settings (figure 2, below) but more so in organisation 2. In each of the two studied organisations there were respondents who had completed their training prior to merger and also those that had seen initial merger actions initiated as they were finalising their initial training. This has an enabled a progressive view of change to be identified and documented in the collected data.

Organisation 1 had a very prescriptive and linear programme which largely followed the policy descriptions, however, very few staff engaged in statutory training packages beyond the use of mandatory induction health and safety and vulnerable person protection online training modules. All respondents in organisation 1 reported having received a centrally provided induction. Very few individuals undertook assessor of verifier ${ }^{2}$ type training.

Organisation 2, based in Scotland, had a very heavy reliance in many curriculum areas on both assessors and verifiers awards for lecturers $\left(\mathrm{SCQF}^{3}\right.$ level 8, QCF level $\left.4^{4}\right)$, they were given in many disciplines far greater priority than academic programmes. It is worthy of note that these are not pedagogy focussed courses but portfolio management training.

Contrary to the published programme, it was revealed in the interviews that none of the respondents from organisation 2 reported receiving a centrally organised induction and several were critical of their introduction to the college.

Susan who lectures in Organisation 2 commented:

I didn't have an induction. I was told 'yes you'll get one [an induction] but it never happened. I was given a timetable with basic info on it and shown where the classes were. I never really got shown anything. It took me about two years to find my feet.

\footnotetext{
${ }^{3}$ SCQF descriptors are a framework used in Scottish education to define the relative level of learning outcomes associated with stages and courses. The framework runs from 1 to 12. Examples from the framework would be: Level 1, introductory pre apprentice; Level 6, standard technical apprenticeship and Level 12, doctorate. Information can be found here: http:/www.scqf.org.uk/framework-diagram/Framework.htm

${ }^{4}$ QCF descriptors used in England and Wales perform the same function as SCQF but run on a scale from Entry level to 8 , entry level 3 being pre-apprenticeship and level 8 being doctorate, see http://www.accreditedqualifications.org.uk/ for further information.
}

Both SCQF and QCF are affiliated with and aligned to the European Qualifications Framework, https://ec.europa.eu/ploteus/en/content/descriptors-page 
Similarly, Thomas, who is a vocationally focused lecturer delivering practical training was also frustrated:

I got next to no support when I started, it was the guys I worked with who sorted me out. I never saw anyone from anywhere else in the college and on my first day I was in a class by 10 o'clock on my own. I never got an induction, ha, still haven't five years later!

Organisation 1 had maintained through its merger process, a focus on induction and training provision by adopting very early on in the organisational merger the accepted model of the larger college.

There was not such an agreement in place within organisation 2 which was still trying to re-develop its programmes post-merger. However, the interview data coupled with observation of practice in organisation 2 revealed a system in some turmoil after several years of pre and post-merger reductions in funding, changing leadership and focus.

The observed practices represented in figure 2 (below) show a snapshot of a dynamic picture within organisation 2 where respondents had reported a variety of experiences, for example, no induction at all to a short curriculum area introduction with a line manager. Organisation 1 showed a fairly static approach to its provision with all respondents who were graduates of the programme reporting very similar experiences.

Figure 2: Actual professional formation models employed*
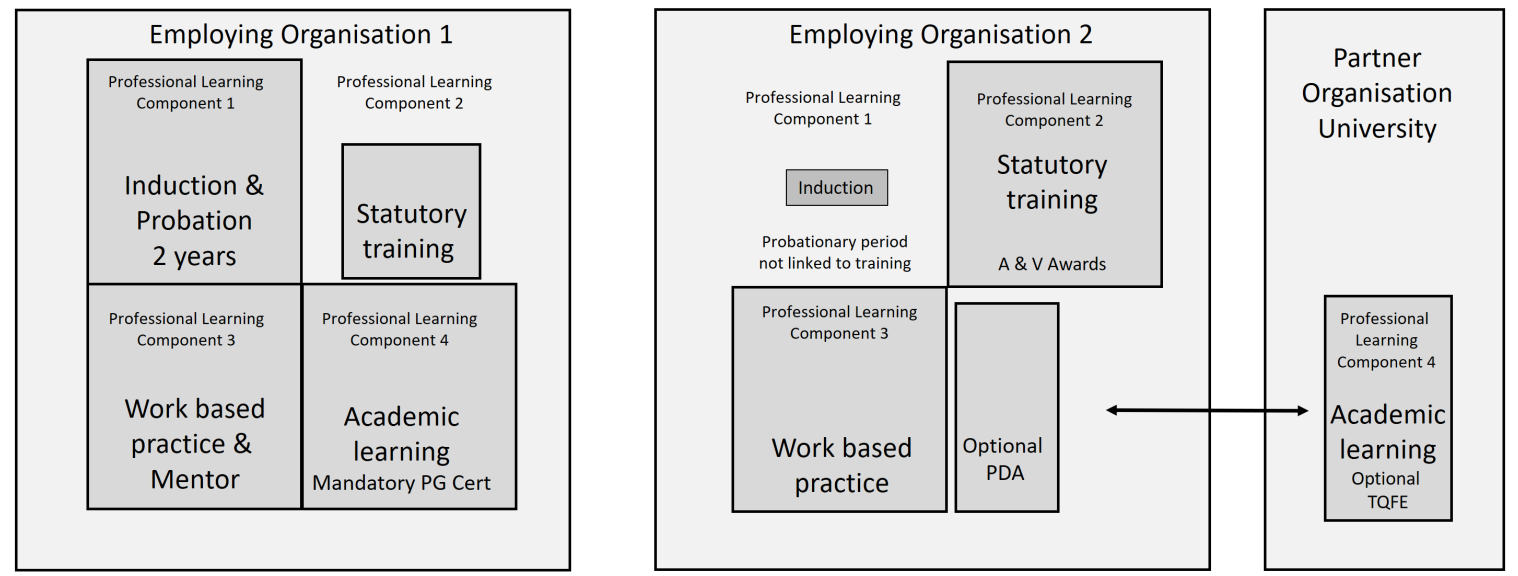

*Figure 2 gives a representational view only but serves to highlight the differing foci of the models of training employed between the two case studies.

Organisation 2 showed a very changing picture over time. What was distinct in the data was that the published training policy and actual practice within the organisation 2 had become significantly removed from each other, i.e. what was being enacted within the organisation was not what was stated in the college published documentation. An example of this was the plan that all new staff would be 
able to undertake and complete the $\mathrm{TQFE}^{5}$ within three years of starting their employment, none of the respondents had been able to do this and very few had had any induction beyond an online software based introduction. This was a decreasing picture over time that had started prior to merger in at least two of the legacy organisations. This finding was significant and interesting in a further aspect giving rise to more complexity to the situation discovered. The provision of mentors was linked directly to the enrolment on supplied courses of learning, if access to TQFE or PDA was delayed so to was access to an official mentor, this is discussed in more detail in the next section.

\section{The role and influence of mentors}

Organisation 1 operated a named mentor programme, this became much more apparent through interview responses which supported the provided documentary evidence. Each new and training member of staff were reportedly assigned a mentor within their own academic area (area manager appointed). The role of the mentor reportedly covered several aspects. Primarily the mentor was assigned to aid the new lecturer in a period of settling into the role and then latterly to provide both support and assessment (teaching observations) in formal lecturer training. A formal process, documented and recorded, was followed by the mentors in organisation 1.

In organisation 2 there was no formal mentor programme beyond the remit in the defined role of the lecturers that provided the teaching for the lecturer education courses (PDA). Lecturers who were enrolled on university provided TQFE courses received support from university tutors, but the mentoring activities associated with the courses were carried out by the same part time staff within the college itself. There were only two of these staff (full time equivalent) working across several campuses at the time of data collection with mentoring responsibility for well in excess of 150 staff.

The work of the mentors in both organisations was highlighted as beneficial by the respondents lecturers. Comments were made in interviews in reference to both officially assigned mentors and the support and mentoring received unofficially from peers.

Elen, a lecturer in a social science related subject in Organisation 1 with nearly ten years' experience made the following observation:

During my training the support from my mentor and help from colleagues was far more influential than the training I was receiving. The training was interesting but I learned much more from observing teaching and working with colleagues.

Mathew, a lecturer in a science based subject in Organisation 2 in Scotland shared a similar perspective:

During my TQFE I relied heavily on Carol [pseudonym for mentor]. I struggled with the distance learning and didn't find the study useful. I could ask Carol for help and she would

\footnotetext{
${ }^{5}$ Degree level (undergraduate and postgraduate dependent on previous qualifications of individuals) university delivered initial lecturer training course. 60 credits delivered over 1 year (full degree $=180$ credits).
} 
be, well like, I'll come over or you should read this paper or that book. She must have had a dozen people like me but really knew her stuff and was really helpful. [...] Because my course [TQFE] was outside of college I didn't have time in work to study and couldn't see how the theory stuff worked in workshops.

The role of the mentor was underplayed in the supplied documents in the original document analysis. It was only in discussion with the relevant managers in each college that information emerged. A mentor's handbook for Organisation 1 was produced and supplied to this project on request. There was no official documentation related to mentoring for Organisation 2, this information was requested from the relevant lead person in this area but assurance was received that no such document existed.

The role of the mentor in both organisations came through strongly in the data but was constructed differently. Organisation 1 had an established mentor programme that had demonstrable influence on candidates in training programmes. Organisation 2 did not have the same level of support from mentors and as a consequence, they featured less prominently in the documents supplied and the accounts of the respondents.

\section{Links between learning and work influenced choices of further learning}

On setting out to conduct this research, one of the initial aims was to assess the efficacy of the academic learning courses provided by each organisation. However, the interview data revealed few differences between the perceived efficacy of the university courses of graduates of both systems. Some of the expectations placed on the externally provided university course were focused primarily on the practical aspects of developing teaching skills for practice. Much of this was not part of the curriculum of the academic courses and was seen in the document analysis as being part of the development achieved through supported and immersive training i.e. developed through supported teaching practice. The graduates from the programmes utilised in Organisation 2 reported a greater level of disconnection between work based practice and academic learning than their counterparts in organisation 1. Their teaching (outside of that assessed by the university) was not seen as developmental and many held the perception that the majority of learning was supposed to be achieved through university provided provision. Support from the organisation itself was reported to be lacking and the respondents struggled to place their academic course within the broader scope of their work and role.

Thomas who teaches engineering and practises in Scotland, focussed on what he perceived to be missing from the course of training he undertook and illustrates the issue of lack of influence between academic learning and practice impacting his choices of ongoing learning: 
There should have been much more training on working with people, class control and discipline, whenever it was raised we were just told by the [university] lecturers to not get involved. There was very little relevance to what I was doing in class and I got no support.

Similarly, Sara who also works as a science subject based lecturer in Organisation 2 in Scotland was surprised at her experiences when she undertook her TQFE on a part time basis whilst working full time:

What shocked me was the complete lack of interest from the [employing] college. When I asked my manager if I could do it [TQFE] I was asked, 'what do you want that for?' It was a real shock. Some of my colleagues were actively trying to avoid it and were annoyed with me for doing it! I had a mentor who was nice but she had so many people to support I didn't feel I could bother her. [...] To be honest I didn't really do any of the work in college, even my observation by my mentor was done quickly and signed off in a rush. I've never bothered with that sort of training again.

The experiences of graduates from organisation 1 were quite different to that of Thomas and Sara and their peers in Organisation 2. The supplied programme of training in Organisation 1 in Wales appeared to be more effective in linking all of the aspects of the programme and as such, the respondents from this college were able to make clear links between their university course and their everyday practice. The following extracts from interviews reflect the opinions of the respondents who commented specifically on this from Organisation 1.

Dewi who has taught in organisation 1 for over ten years advocated the benefits of the practical aspects of his training and reflected positively on his experiences:

The most useful part of the training was definitely the practical work with other teachers and observing different teaching styles, I could link the theory to the reality of teaching and my mentor was able to help after observations. [...] Because the course [PGCE] was delivered in house everyone did it and my colleagues all got it, they knew why I was asking certain questions and they mostly cared and helped.

Carys, an arts based lecturer in Organisation 1 echoed these sentiments:

I did my PGCE part time and worked part time. I was given space in my timetable for development and all my boss wanted to see was that I was using what I was learning. The PGCE was really just like another day at work.

This finding shows that within the two studied organisations the links between the university provided course, and the in house support and extra training programmes, worked more effectively for the student lecturers when links between study and practice were pro-actively constructed and enacted by the employing organisation. Where the teaching practice and university provided theory were not 
appropriately linked or adequate support given in practice, student lecturers were less able to situate their learning in work based practice and as such found less utility and satisfaction in the training.

\section{Impact of initial training on engagement with ongoing professional learning}

When asked to reflect on the types of training undertaken since graduating from their respective lecturer education programmes, respondents gave a very broad set of responses but a theme soon emerged from the data. Graduates from the different training programmes in the two case study colleges prioritised different types of professional learning. Several of the respondents reported that their choices regarding further training and professional learning were related to attempts to bridge perceived gaps in knowledge and seek solutions to specific problems that they had encountered. This is exemplified by William who teaches in Organisation 1:

"I simply wasn't classroom ready at the end of my training, there were so many gaps that I felt I needed and wanted to learn more. It's not really a bad thing I suppose but I expected to feel more ready."

William's comment was quite typical of the graduates from organisation 1 in relation to the completion of their programme of study. This was not necessarily reported as a problem but more of a statement of fact and accepted as the norm. The respondents were open to ongoing learning and felt empowered to seek opportunities to pursue it. This theme was further expanded on by Elen from Organisation 1:

PGCE was OK, it really just gave a language to what I was already doing. It was so embedded in the department and college though that it felt like a rite of passage. [...] My most useful training has been shorter courses and collaborations with people after it [PGCE] finished.

The graduates from organisation 2 reported a greater engagement with subject specialism learning than their counterparts from Organisation 1. Several confessed to avoiding further pedagogic development due to a feeling of disengagement brought about through perceived negative experiences whilst undertaking initial training. Pedagogy was simply seen as less important than the subject specialism itself.

Sara who teaches languages based subjects in organisation 2 voiced strong opinions on this:

My [initial] training does influence my CPD [continuous professional development] choices but not in a good way. I avoid CPD to do with teaching and learning because I have been turned off to it. I always seek out subject specialist CPD because I felt it was missing from my training, it was too generic.

These comments were echoed by Eve who also teaches in Organisation 2 and holds a promoted post:

I would always choose to attend subject specific training over teaching related CPD, I am fully qualified, I feel I need to spend my very limited time on my subject training. 
This suggests that although initial training has a varied impact on general engagement with continued professional learning and attitudes towards continuous development, the model of training respondents had undertaken, and the cultural and organisational emphasis on professional learning, appears to have an impact on the type of ongoing learning being sought out, prioritised and engaged with.

\section{Comments and Points for Consideration in Practice}

This research has revealed and highlighted several key points in relation to the scope, focus, structure, content and situational context of initial education programmes for lecturers in the studied colleges.

The formation and reach of programmes designed to 'train' new lecturers, seems to require a synergistic approach to design, structure and implementation. Where the varying components of programmes are complementary they seemingly consequently afford greater benefit than the sum of their individual parts taken in isolation.

This research revealed that in both studied colleges the planned and published programmes of professional learning were not enacted as designed. This was highlighted in the accounts and responses of the research participants who identified where promised aspects of professional learning were absent, it had a negative impact on their learning and development (see comments regarding induction for example). In several cases the respondents identified situations where they had to either forgo supported learning opportunities or seek the knowledge elsewhere (as evidenced by responses related to mentoring and induction practices). This has echoes of the scenarios discussed by Orr (2012) where learning to cope instead of learning to teach had been the reality for some in that reported study. The issues related to programme enactment and the reported lack of support from respondents are not separate but both point towards the importance of the broader scope of professional learning programmes in colleges and their contextual situation and grounding in practice. This finding suggests that a stratification or delineation between stages of career learning is perhaps present and there is a consequential failing in the continuity between induction, initial lecturer education and continued career long learning. It is suggested that organisation could benefit from looking closely at the planned structures of learning and critically examine practice and evaluate to what extent they are meeting these proposed programmes and the learning needs of colleagues at all career stages. Where sound induction practices are absent or have been commuted to online modules it is suggested that a reintegration of a formal and thorough continuing induction programme is embedded into a programme of continuous learning.

Where mentoring was available and supplied as part of the professional learning of the respondent lecturers, it was recalled and described very favourably. As highlighted by Ingleby (2011) where the role of mentor was considered to be a professional position, it was very successful. However, these 
individuals, in this study, were reported to be spread very thinly across a very broad cross section of colleagues needing support (organisation 2). There was evidence of equal praise levelled at the work of experienced individuals that were not acting as mentors alone, but also as colleagues in the same department with the same subject specialisms.

An unexpected finding of this study is closely related to the work of mentors in the studied colleges, the influence of informal or perhaps more appropriately, unofficial mentors. The support afforded by colleagues to new members of teams was a consistent theme in the interviews conducted. Where gaps in support and training provision for new lecturers were evident, they were filled (in many different ways) by colleagues. This finding echoes that reported by Slade (2011) recalling the importance of colleagues in the induction, mentoring and training of public sector workers such as the Police. Much of the learning carried out is in practice, embedded into teams and witnessing, participating and enacting the role with a gradual extension of skills and confidence leading towards competence and autonomy.

The respondents in this study identified that induction, timely access to structured programmes of learning, access to a mentor, and integrated supported practice were all influential in their perceived transition from trainee to competent and confident qualified lecturer. However, it is worth noting that in some cases, early experiences of initial lecturer education programmes reportedly had an effect on the respondents engagement with, and choices of, ongoing professional learning. This then suggests that instead of being treated as discrete activities, the acts of initial lecturer education and continuing professional learning are inextricably linked and can be usefully thought of as significant and important parts of continuous and career long learning. When new staff are employed into an organisation the opportunity to begin their pathway through supported learning starting with thorough and meaningful induction practices supported by mentors from the outset and through all stages (Page, 2013) could see broader cultural advantages over time within organisations (Brandon \& Charlton 2011).

It is therefore suggested that in designing and managing professional learning programmes, the provision of thorough induction practices, initial education, mentoring, practice embedded work based learning and ongoing career long professional learning are all integral parts of one continuous process. This study found that where these integral parts were linked the respondents recalled positive impacts to practice and where they were not linked or absent, negative impact was frequently recalled and had a lasting effect in practice.

\section{Closing Comments and Limitations}

This research has highlighted several areas of interest that will form the basis of continuing study, however its limitations must be recognised. 
This research was conducted under the premise of self funded doctoral study and as such limitations in funding restricted the number of case study sites informing the work. It is recognised that the findings of this study speak to a localised incidence of phenomenon and over generalisation of the findings at this stage could be problematic and, as such, every effort has been made to avoid this practice. However, the phenomenon recorded and discovered were the genuine experiences of individuals working in colleges in what could be described (in the present FE climate in the UK), as typical and familiar conditions. Although taken from two current college organisations, the samples studied hailed from a rich heritage of legacy organisations each with their own histories, traditions and cultures. This study has in a small but significant way begun to study the important and interesting area of ongoing impact of initial lecturer education programmes on the lecturers themselves. This area warrants the attention of a continuing research project to both test and expand its findings and assertions.

Nevertheless, this research has produced findings of potentially international importance and interest by challenging some of the assumptions made on a national level about the efficacy, relevance and impact of initial training programmes. The findings related to the described impacts of initial lecturer training and organisational support for career long professional learning have significance for all lecturer trainers and educational leaders operating across the international context of the vocational and further education sector. This research also acts as a case study informing the wider professional learning literature by looking at learning networks in recently merged, complex and change focused organisations.

\section{References}

Asif, F., 2013. Philosphizing the Concepts "Teacher Training" and "Teacher Education." International Journal of Multidisciplinary Academic Research, 1(1), pp.15-21.

Avis, J. et al., 2012. Teacher education for vocational education and training : a comparative study of the Scottish and English systems set within a European context. Scottish Educational Review, 44(2), pp.14-23.

Bathmaker, A. \& Avis, J., 2005. Becoming a lecturer in further education in England: the construction of professional identity and the role of communities of practice. Journal of Education for Teaching: International Research and Pedagogy, 31(1), pp.47-62.

BERA, 2011. Ethical Guidelines for Educational Research, London: British Educational Research Association.

Bowen, G., 2009. Document Analysis as a Qualitative Research Method. Qualitative Research Journal, 9(2), pp.27-40.

Brandon, T. \& Charlton, J., 2011. The lessons learned from developing an inclusive learning and teaching community of practice. International Journal of Inclusive Education, 15(1), pp.165178.

Crist, J. \& Tanner, C., 2003. Interpretation/Analysis Methods in Hermeneutic Interpretive Phenomenology. Nursing Research May/June, 52(3), pp.202-205. 
Drever, E., 2003. Using Semi-structured Interviews 2nd ed., Glasgow: University of Glagow.

Eraut, M., 2004. Informal Learning in the Workplace. Studies in Continuing Education, 26(2), pp.247-273.

Eraut, M., 2007. "Learning from Other People in the Workplace." Oxford Review of Education, 33(4), pp.403-433.

Filliettaz, L., Durand, I. \& Trebert, D., 2015. Learning Through Verbal Interactions in the Workplace: The Role and Place of Guidance in Vocational Education and Training. In Francophone Perspectives of Learning Through Work. Geneva: Springer International, pp. 279-301.

Fossey, E. et al., 2002. Understanding and evaluating qualitative research. Australian and New Zealand Journal of Psychiatry, 36, pp.717-732.

Fuller, A. \& Unwin, L., 2014. Nurturing occupational expertise in the contemporary workplace: An "apprenticeship turn" in professional learning. In T. Fenwick \& M. Nerland, eds. Reconceptualising professional learning. Abingdon: Routledge, pp. 85-98.

Gadamer, H., 1998. Truth and Method 2nd ed., New York: Continuum.

Husband, G., 2015. The impact of lecturers' initial teacher training on continuing professional development needs for teaching and learning in post-compulsory education. Research in PostCompulsory Education, 20(2), pp.227-244.

Ingleby, E., 2011. Asclepius or Hippocrates? Differing interpretations of post-compulsory initial teacher training mentoring. Journal of Vocational Education \& Training, 63(1), pp.15-25.

Lucas, N. \& Unwin, L., 2009. Developing teacher expertise at work: in-service trainee teachers in colleges of further education in England. Journal of Further and Higher Education, 33(4), pp.423-433.

van Manen, M., 1990. Hermeneutic Phenomenological Writing. In P. Smith, ed. Researching Lived Expeience. New York: State University of New York Press, pp. 111-133.

Maxwell, B., 2014. Improving workplace learning of lifelong learning sector trainee teachers in the UK. Journal of Further and Higher Education, 38(3), pp.377-399.

O’Brien, J., 2016. Professional Learning: Concepts, Models and Empirical Practice. Professional Development in Education, 42(1), pp.1-4.

Orr, K., 2012. Coping, confidence and alienation: the early experience of trainee teachers in English further education. Journal of Education for Teaching : International research and pedagogy, 38(1), pp.51-65.

Orr, K. \& Simmons, R., 2010. Dual identities: the in-service teacher trainee experience in the English further education sector. Journal of Vocational Education \& Training, 62(1), pp.75-88.

Oude Groote Beverborg, A., Sleegers, P. \& van Veen, K., 2015. Fostering teacher learning in VET colleges: Do leadership and teamwork matter? Teaching and Teacher Education, 48, pp.22-33.

Page, D., 2013. The recruitment and transition of construction lecturers in Further Education: the perspective of middle managers. Educational Management, 41(6), pp.819-836.

Slade, B., 2011. Rural Police Practice in Scotland: The Case for a Sociomaterial Approach.

Tongco, M.D.C., 2007. Purposive sampling as a tool for informant selection. Ethnobotany Research and Applications, 5, pp.147-158.

University of Dundee, 2015. TQFE. www.dundee.ac.uk. Available at: $\mathrm{http} / / / \mathrm{www}$.dundee.ac.uk/study/ug/teaching-qualification-further-education/ [Accessed October $16,2015]$.

University of Stirling, 2015. TQFE. www.stirling.ac.uk. Available at: http://www.stir.ac.uk/undergraduate-study/course-information/courses-a-to-z/school-of- 
education/teaching-qualification-in-further-education/coursetitle-19809-en.html [Accessed January 1,2016$]$.

Wenger, E. \& Lave, J., 2002. Legitimate Peripheral Participation in Communities of Practice. In J. C.

R Harrison, F Reeve, A Hanson, ed. Supporting Life Long Learning. London: Routledge Falmer, pp. 111-126.

Yin, R., 2011. Qualitative Research from start to Finish, London: The Guildford Press. 